\title{
Kiwifruit bacterial canker in 'Hayward' kiwifruit: Design of a quantitative questionnaire for kiwifruit growers
}

\author{
K.J. Froud ${ }^{1}$, N. Cogger ${ }^{1}$ and R.M. Beresford ${ }^{2}$ \\ ${ }^{1}$ Massey University, Private Bag 11-222, Palmerston North 4442, New Zealand \\ ${ }^{2}$ The New Zealand Institute for Plant \& Food Research Limited, Private Bag 92169, \\ Auckland Mail Centre, Auckland 1142, New Zealand \\ Corresponding author: karyn.froud@orcon.net.nz
}

\begin{abstract}
Longer term effects of Pseudomonas syringae pv. actinidiae biovar 3 (Psa) on 'Hayward' kiwifruit (Actinidia chinensis var. deliciosa) production are unclear and there is uncertainty about what impact orchard activities could have on disease prevalence. The aim of the present study was to determine the validity of the data obtained from a crosssectional observational study using a quantitative postal questionnaire on disease and risk factor prevalence from commercial growers of 'Hayward'. The questionnaire was sent to 1669 growers and 442 responded (26\%), a response rate similar to that of other agriculture surveys in New Zealand. Non-responses were analysed against a range of factors to assess response bias. There was a higher response rate from organic growers, and those affiliated with specific packhouses. There were no differences between responders and non-responders according to the period of time their orchard had been infected with Psa or to orchard productivity. We conclude that a postal questionnaire was an effective way to obtain quantitative disease, risk factor and hygiene data from commercial producers.
\end{abstract}

Keywords Actinidia deliciosa, risk factors, 'Hayward', cross-sectional, quantitative survey, postal, non-response bias.

\section{INTRODUCTION}

Bacterial canker in kiwifruit is a serious disease caused by Pseudomonas syringae pv. actinidiae biovar 3 (Psa), which was first reported in New Zealand in November 2010 (Everett et al. 2011). Psa affects kiwifruit plants by causing leaf spotting, shoot and cane dieback and stem cankers. The whole vine may be affected in severe cases leading to death and/or removal of the vine from the orchard. The disease had an immediate and major effect on the productivity of gold-fruiting Actinidia chinensis var. chinensis
'Hort16A' vines, which have now largely been removed and replaced with a more resistant gold cultivar ('Zesy002'). However, green-fruiting A. chinensis var. deliciosa 'Hayward' vines in New Zealand are continuing to be grown in the presence of the disease (Ferrante \& Scortichini 2009; Ferrante et al. 2012; Vanneste 2012) with limited impact of Psa on productivity (Froud et al. 2014).

Experimental studies are commonly used to investigate the epidemiology of plant diseases. However, they may not always be feasible where 
multiple risk factors are involved (Thebaud et al. 2006; Froud et al. 2014). When investigating multiple risk factors, observational studies offer several advantages (Dohoo et al. 2009a). Observational studies provide insights on the performance of recommended management practices in animal health when applied by farmers, rather than researchers. This approach can be used to identify practical reasons why interventions may not work in the manner predicted by experimental studies. This type of study design has been rare in plant protection research although a few examples do exist (Dallot et al. 2004; Thebaud et al. 2006; Everett et al. 2007; Vicent et al. 2012; Froud et al. 2014; Cogger \& Froud 2015).

We chose to use a cross-sectional study based on an industry survey, to investigate Psa prevalence, risk and hygiene factors in 'Hayward' orchards. Cross-sectional studies can be used to quickly identify which potential risk factors are important in disease developing in a population. They are also useful for determining the prevalence of pests, pathogens and possible risk factors for disease (Dohoo et al. 2009a; Rothman 2012).

There are challenges to developing a survey that will result in a high response rate of valid, unbiased data. This paper describes the development, design and distribution of a questionnaire to kiwifruit growers. It discusses survey design principles and assesses any response bias. Response bias is a form of selection bias, as it relates to those who respond to the survey compared with those who did not.

\section{Development of the questionnaire}

The questionnaire was developed in a three-step process:

Step 1. A workshop to identify key risk factors

Risk factors were identified from information provided by technical experts in Zespri International Limited (Zespri) and Kiwifruit Vine Health (KVH) plus two kiwifruit grower representatives. This allowed the development of a causal web diagram, which was used to visualise postulated relationships between risk factors and to identify any potentially confounding variables on which data would need to be collected (Figure 1) (Dohoo et al. 2009a; Rothman 2012). Collection of data for potential confounding variables is essential when an observational study is used to investigate risk factors, as the data are not randomised to address differences in the source population, as it would be in an experimental trial (Froud \& Cogger 2015).

Step 2. Development of the draft questionnaire

The questionnaire was developed following the principles outlined in Dohoo et al. (2009b). A key concern when using a cross-sectional study is the temporality of factors; that is, did exposure to risk precede the development of disease? In this study the growers were being asked to describe their experience of the disease in their orchards in February 2013. Therefore the questions were structured to focus on factors that existed or occurred prior to February 2013. In addition disease onset data specific to the orchard block of interest would be requested from the grower. The questionnaire was then circulated to Zespri and $\mathrm{KVH}$ technical experts to seek consensus on its content and to modify where necessary before pre-testing.

Step 3. Pre-testing of the questionnaire

Pre-testing aimed to identify any questions that may have been confusing, ambiguous or misleading and also to determine if the layout and instructions given to respondents were suitable. Pre-testing also aimed to identify additional questions and additions to existing closed question options. Pre-testing also enabled us to determine if there was any reluctance to answer specific questions and to estimate the time required to complete the questionnaire.

The pre-testing methodology involved face-to-face interviews with 10 growers in the Eastern Bay of Plenty in January 2013. The growers were given information about the purpose of the pre-test and then asked to review the questionnaire cover letter. Growers were asked to complete the questionnaire for a specific block on their orchard. The grower and researcher discussed each question during completion to determine whether the language was suitable, the intent of the question was obvious, the tick-box answers were exhaustive and clear and whether interpretation was consistent between the researchers and 


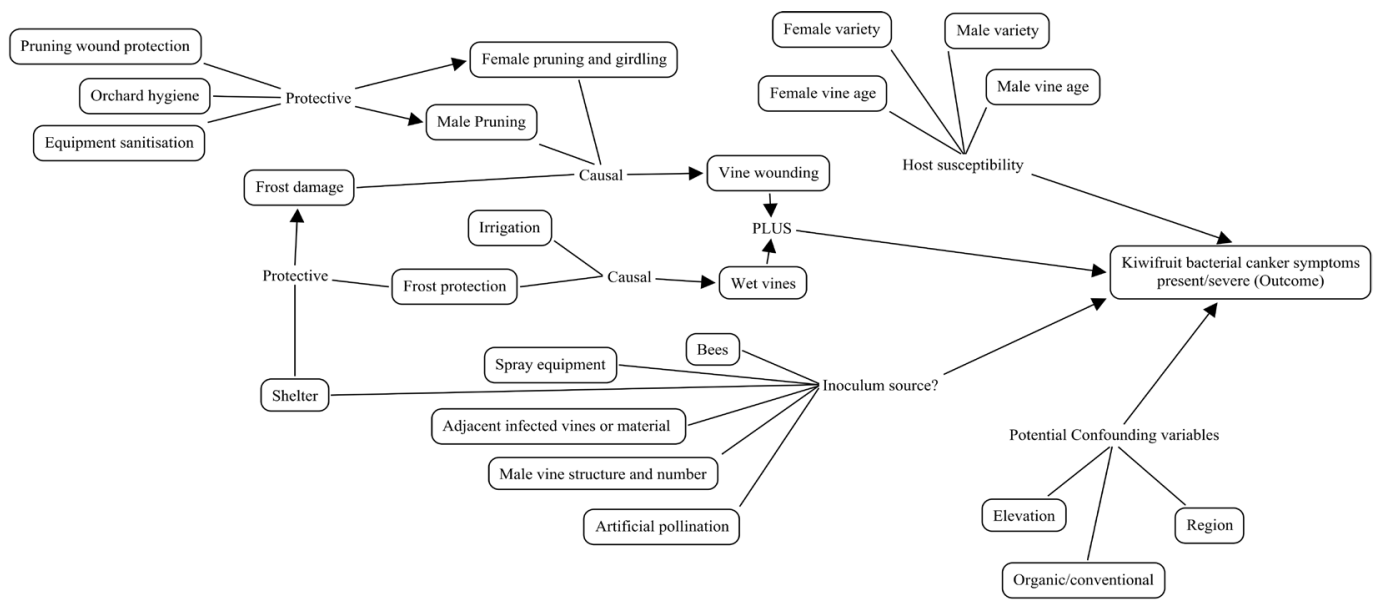

Figure 1 Postulated causal diagram of factors that could increase or decrease the risk of kiwifruit bacterial canker symptoms in 'Hayward' kiwifruit blocks and how these factors may be associated with each other or with potentially confounding variables.

respondents. The first nine growers interviewed received the draft questionnaire while a tenth grower received a modified version based on feedback from the initial nine growers. The last section of the draft questionnaire required the grower to provide detailed orchard management and spray diary information. Five growers were asked to fill out this last section of the questionnaire and the remaining growers were asked to comment on whether they felt they could answer the questions accurately, based on the records they routinely keep. All growers were asked if the list of vine management activities was clear and to note any omissions. The time taken by each grower to complete each question was also recorded. Overall the grower interviews for pre-testing the questionnaire took between 60 and $90 \mathrm{~min}$.

Growers involved in the pre-testing found that the questions were easily interpreted and they only suggested minor changes to the language. All growers were keen to participate and nine out of 10 growers stated they would very likely complete the questionnaire if it arrived in the post. Of these 10 growers, eight did actually fill in and return the postal questionnaire. Pre-test participants estimated that if they completed the questionnaire as a postal survey, it could be completed in 45 to 60 min if they had vine management records to hand.

There is evidence that more people will participate in a survey if it is much shorter than 45-60 min (Edwards et al. 2002). Therefore there was a risk that the time to complete this questionnaire would reduce the response rate. We considered that a monetary incentive (a Zespri-funded \$20 fuel voucher for each respondent that completed and returned the questionnaire) and the personal interest by growers in Psa would compensate for the rather long time required to complete the questionnaire. Both of these factors are proven to increase response rates (Edwards et al. 2002).

Questionnaires were sent to all Zespri registered growers that met our eligibility criteria (Figure 2) rather than a sample, which also aimed to maximise the number of questionnaires returned for analysis. Pre-testing was an important part of the process that ensured that the majority of questions would elicit answers that were appropriate for subsequent analysis.

\section{Content of the questionnaire}

Growers were required to report detailed information about the occurrence of disease 


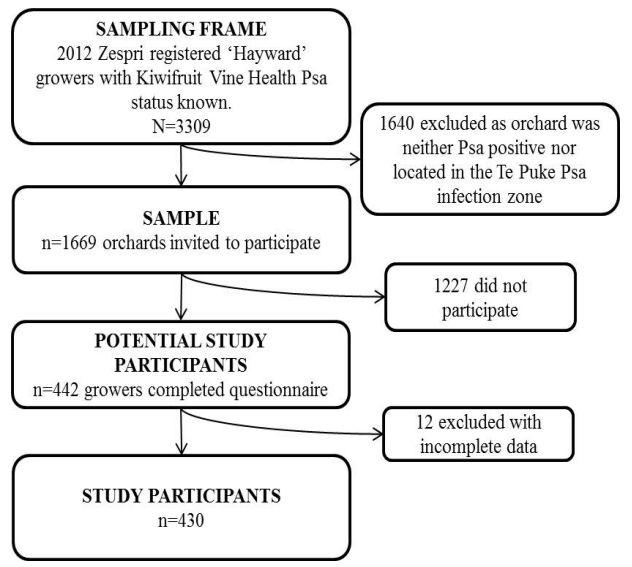

Figure 2 Sampling plan showing selection of a sampling frame and the eligibility criteria for inclusion in the study.

symptoms and management of vines at the level of a 'Hayward' block rather than the cultivar or orchard level. A single block was selected as there is less variability in the management of vines within a block when compared with how different blocks of the same cultivar within an orchard are managed. Asking growers to respond for each of the 'Hayward' blocks in the orchard would have generated clustered data and significantly increased the time taken to complete the survey which could have risked a reduced participation rate and/or data quality.

A block was randomly selected within each orchard from the sampling frame using an algorithm written in the ' $\mathrm{R}$ ' freeware statistical package version 3.0.1. Random selection of blocks was to avoid selection bias such as orchardists' selecting their 'most average', best or worst block depending on what they thought was most relevant to the study.

The final questionnaire comprised a covering letter and the questionnaire proper in three sections. The covering letter explained briefly the purpose of the survey and indicated the randomly selected block on which the grower would report. The cover letter contained only the minimum information to enable respondents to answer the questionnaire accurately. The research aim was not included in the letter to avoid response bias where respondents answer in a way that they consider helpful for the study.

The first section of the questionnaire focused on the disease with questions relating to the presence of symptoms between March 2012 and February 2013. The second section sought information on host, environment and orchard management factors. The third section was optional for growers to complete. It aimed to collect detailed temporal information on vine and management activities between March 2012 and February 2013. Answers in the third section needed to be accurate as they were to be used to combine daily risk exposures with daily disease prediction model data.

There was some concern that time required to answer the third section might discourage some growers from returning the survey. To reduce that possibility the following note was included at the start of section 3: "Thank you for filling in the survey to this point. We are aware that all growers may not have access to the required information to fill out the following section (section 3) accurately. If you do not have this information available please return your survey following completion of section 1 and 2 and leave section 3 blank. If you do have access to the information that would allow you to complete section 3 please do so as this is a valuable part of this survey."

\section{Distribution of the questionnaire}

Zespri provided block and production data for all registered 'Hayward' growers producing kiwifruit for export in 2012 and KVH provided data on Psa status and date of detection in orchards. Orchards that were recorded in both data sets formed our sampling frame (Figure 2), which comprised 3,309 kiwifruit growing operations in 17 regions throughout New Zealand. To be eligible for inclusion in the study, an orchard had to have producing 'Hayward' vines as of harvest in 2012 and either be located in the Te Puke Psa infected region or classified as infected as of 1st January 2013 from another growing region. A decision was made to include all orchards in Te Puke as 
$98.5 \%$ of orchards in the region were confirmed as infected as of 1 January 2013. The method used to define which orchards were infected (cases) changed during the outbreak. Initially, cases were defined by the Ministry for Primary Industries as orchards with Psa confirmed by a diagnostic test. Later in the epidemic, when the number of infected orchards had increased substantially, KVH provided the case definition as orchards with Psa confirmed either by a diagnostic test or through the observation of visual symptoms of bacterial canker and confirmed by a technical representative of Zespri, $\mathrm{KVH}$, a packhouse or similar industry body. The symptoms accepted as evidence of Psa during the growing season were blackened canes or shoots with die-back and/or stem wilting. In winter diagnostic symptoms were weeping cankers with or without red or white exudate. The date of a positive diagnostic test, or the date visible signs of disease were reported, were recorded in the database as the date of confirmed infection. The KVH dataset also contained data regarding the elevation and the main pack-house for each orchard.

The options for distribution of the survey were telephone survey, online survey or postal survey. Phone-based surveys are known to improve response rates (Mannetje et al. 2011). However, for this study it was not considered economically viable because of the large sample size and the length of the questionnaire. If the targeted population is generally familiar with online technology and has easy internet access then there are advantages in using an online format. These are improved data quality, completeness of responses to individual questions, and the ability to restrict access to irrelevant questions (Lonsdale et al. 2006; Kongsved et al. 2007; de Bernardo \& Curtis 2013). However, online distribution of the survey was not considered practical as rural internet access can be problematic in the Bay of Plenty and the complexity of Section 3 regarding timing of crop management activities would have made it difficult to configure. Using a postal format has been shown to increase response rates compared with internet-based surveys, especially for older respondents. Postal surveys also reduce response bias, as all eligible participants can access the survey (Kongsved et al. 2007; Borkan 2010; Partin et al. 2015). Therefore a postal survey was selected to disseminate the questionnaire. If there were insufficient responses from the postal survey, a second round of postal questionnaires to non-responders was planned and if necessary follow-up phone surveys.

To maximise the response rate to the postal questionnaire, Zespri placed advanced notice of the survey in the industry newsletter in late February 2013, offered a \$20 fuel voucher to growers on receipt of their completed survey by the due date, and included a post-paid return envelope.

The questionnaire was sent by Zespri to 1669 eligible 'Hayward' growers on 14 March 2013 with the request to return them before 12 April 2013. A reminder to complete the surveys was disseminated by Zespri in early April by email and included requests to packhouses to encourage their growers to return their surveys.

\section{Response to the questionnaire}

The response rate for the questionnaire was $26 \%$ (442 from 1669 eligible recipients). This rate of return is consistent with most kiwifruit industry questionnaires (M. Jopling, Zespri Ltd, personal communication) and also typical of New Zealand farmer response rates to epidemiology and on-farm hygiene questionnaires (Greer \& Teulon 2003; Van Toor \& Teulon 2006; Neumann et al. 2013; Rosanowski et al. 2013). Twelve respondents were excluded from further analysis either because they did not provide information about the disease status of the block $(n=9)$ or other key information was missing $(n=3)$. Therefore, the final dataset comprised data from 430 'Hayward' kiwifruit blocks.

\section{Response bias}

Non-responders can influence the validity of a study of this kind. With more than $70 \%$ of growers not returning the survey, bias in the results could occur if those who did not respond differed in a systematic way from the rest of the grower population. This type of bias is of concern when estimates of disease prevalence are extrapolated to 
a range of groups. For example, if the prevalence of severe symptoms was higher in high elevation orchards than in low elevation orchards, but more high elevation based growers had responded to the survey, any estimate based on such survey results would inflate the estimated disease prevalence on low elevation orchards. However, the primary objective of the present study was to collect data to identify risk factors associated with the introduction of Psa onto an orchard, and with severity of symptoms. A response bias is less likely to impact identifying risk factors than it would be in estimating disease prevalence in the population. This is because observational studies to determine factors that alter risk are based on biological processes and as such do not need to be based on a statistically representative population (Rothman et al. 2008). For example if a study conducted in 'Hayward' vines in one location showed that a management technique decreased disease, it need not necessarily be repeated in another location except to demonstrate a potential causal relationship or to determine if the size of the effect depends on other factors that may vary between the regions.

To analyse the potential for response bias, a range of factors for which information existed in the Zespri and $\mathrm{KVH}$ data sets were compared with whether a 'Hayward' grower responded or did not respond in order to identify any differences between factors that were common to non-responders. Response status was assigned based on those who responded (coded as 1) and those who did not respond (coded as 0). Data included the following variables: region, kiwifruit cultivar 'Hort16A' presence on the orchard, the main contracted packhouse for the orchard, organic or conventional management, orchard size (Ha), productivity in 2011 and 2012 (tray equivalents per hectare) and the number of days since Psa had been detected on the orchard.

For continuous data, box plots were constructed to visualise the relationship between response status and the orchard size (Ha), productivity in 2011 and 2012 (tray equivalents per hectare), and the number of days since Psa was first detected on the orchard. For each continuous variable, the significance of its relationship with response status was assessed using a two-sample t-test. Comparison of categorical variables was visualised in two-way tables and the relationship between response status and the region, pack-house, presence of 'Hort16A' or organic/conventional management was tested using Chi-squared tests or Fisher's exact test with simulated P-values (where sample sizes were small). Odds ratios for response status for all variables were calculated using simple logistic regression and exponentiation of the log odds.

The response status was not significantly associated with elevation, productivity in 2011 or 2012, days since Psa was first detected or the presence of 'Hort16A' kiwifruit vines. In contrast, organic producers were more likely to respond than those using conventional management (35\% vs $25 \% ; \mathrm{P}=0.04)$.

When all of the regions were compared, there was a significant difference in response status between regions $(\mathrm{P}=0.002)$ with the response in Te Puke (the main kiwifruit growing region) being lower than elsewhere. However, there was no significant difference in response status between any of the larger growing regions $(\mathrm{P}=0.09)$ after regions with less than 50 eligible orchards were excluded. There was a significant difference in the response pattern according to the affiliation of a grower with a particular packhouse $(\mathrm{P}<0.001)$, which was not related to the numbers of affiliated growers supplying a packhouse. Of those packhouses with $>50$ supply orchards there were two with particularly high response rates $(40 \%$ and $35 \%)$ and two packhouses with particularly small response rates (16\% and $17 \%)$. The higher response rate for growers affiliated with two large pack-houses was likely linked to the efforts the packhouses made using grower newsletters and emails to encourage growers to respond. There was also a statistically significant difference in numbers of responders according to mean orchard size ( 4.4 ha for responders vs 4.9 ha for non-responders; $\mathrm{P}=0.02$ ) but the difference between orchard size was only half a hectare which is unlikely to be biologically important with an overall mean orchard size of 
$4.8 \mathrm{ha}$. If there was a greater difference in orchard size between those that responded and those that did not, there could be concern that large orchard management practices differ from much smaller orchards and therefore the results of the survey would not be valid for large orchards.

The higher response rates from organic growers and those who used particular pack-houses suggest some non-response bias may have been present.

\section{Item omission}

From the 430 orchard blocks included in the analysis, the item omission rate was very low with $0.23 \%$ to $1.16 \%$ of respondents not answering a question where an answer was expected. The questions not answered were always among eight particular questions, and of these the two that were most frequently left blank were the age of female and male vines (4/430 and 5/430 of respondents left these blank respectively). All other omitted questions had only one, two or three blanks among the respondents' surveys. On inspection of the data, missing values appeared to be missing at random with only one grower neglecting to answer two questions. This indicates that individual questions were easily interpreted. Although the numbers of omitted answers were very small there was a trend of more omitted answers towards the end of the questionnaire, indicating that the long period of time required to complete the questionnaire was close to exceeding grower tolerances.

\section{CONCLUSIONS}

This study showed that a postal questionnaire was an effective way to obtain disease, risk factor, and orchard hygiene data for a cross-sectional study on plant health. The use of a causal web to visualise factors in the study and to identify potential confounders and possible interactions between variables is recommended when designing observational studies (Dohoo et al. 2009a; Froud \& Cogger 2015). In this study, visualising the causal web aided the development of the individual questions to ensure that data were collected from potential confounding variables. The collection of confounder data in this observational study will be important when the effects of orchard based environmental risk factors for disease are investigated in future analysis of these data.

The pre-testing of the questionnaire ensured that there was a clear understanding of the meaning of the questions by the respondents, providing confidence in the results obtained. If the researcher and the respondent have a different interpretation of a question, then interpretation and validity of results can be fundamentally biased.

This study obtained a typical response rate for this industry despite its length. We attribute this to growers' personal interest in Psa, the encouragement of some packhouses for their growers to complete the questionnaire, and the reward of the fuel voucher. If the cross-sectional study been investigating a less devastating disease, the length of the questionnaire may have reduced the response rate below that sufficient for robust analysis (Edwards et al. 2002; Rolstad et al. 2011). The questionnaire described in this paper was very long and this may have influenced our overall response rate, and the slightly higher item omission rate near the end of the questionnaire.

The availability of industry data allowed us to compare respondents in the context of all potential participants in a survey and identify the potential for response bias between responders and non-responders (Groves 2006; Groves \& Peytcheva 2008; Mannetje et al. 2011). The higher response rates from organic growers and those who used particular packhouses suggest some non-response bias may have been present and care will need to be taken in the future interpretation of the data set to address this.

Non-response may have two implications in a study of this type; firstly if the aim is estimating the prevalence of disease for a population, where bias is known to be present it is important to present stratified results (i.e. report separate disease prevalence rates for conventional and organic growers). The second issue of non-response is the potential for bias around estimates of risk factors if 
there is a correlation between the outcome variable of interest (in our study this is presence of Psa) or key potential risk factors for the disease that could be associated with non-response (Mannetje et al. 2011). In this study there was no difference between responders and non-responders associated with the time period that the disease had been present, a factor which could have affected the validity of future results. The data collected from this survey describe adequately the prevalence of Psa symptoms (Froud et al. 2015) and the range of specific grower management practises, stratified for organic and conventional growers. The data can also be used to investigate risk factors that are associated with the introduction and severity of disease in commercial orchards and will also be useful to determine the relationship between weather risk, vine management wounds, protective spray applications and kiwifruit bacterial canker development.

\section{ACKNOWLEDGEMENTS}

Thank you to KVH for Psa detection data and survey review, to Greg Clark and Shane Max (Zespri International Limited), Jenny Natusch and Richard Klas (kiwifruit growers) for assistance with survey development. Thanks to Tracy McCarthy, Clare Morris, Madeleine Jopling and others (Zespri) for administering the questionnaire, the incentive programme and data entry. We would also like to thank the ten Whakatane region growers who pre-tested the questionnaire, and for their very valuable feedback. This project was funded by the Zespri and Kiwifruit Vine Health Psa research and development programme under contract number V11367.

\section{REFERENCES}

Borkan B 2010. The Mode Effect in Mixed-Mode Surveys Mail and Web Surveys. Social Science Computer Review 28: 371-380.

Cogger N, Froud K 2015. Application of survival analysis to plant protection research. In: Beresford RM, Froud KJ, Kean JM, Worner SP ed. The plant protection data toolbox: On beyond t, F and X New Zealand Plant
Protection Society. Christchurch, New Zealand. Pp. 101-107.

Dallot S, Gottwald T, Labonne G, Quiot JB 2004. Factors affecting the spread of Plum pox virus strain $M$ in peach orchards subjected to roguing in France. Phytopathology 94: 13901398.

de Bernardo DH, Curtis A 2013. Using Online and Paper Surveys: The Effectiveness of Mixed-Mode Methodology for Populations Over 50. Research on Aging 35: 220-240.

Dohoo IR, Martin W, Stryhn H 2009a. Veterinary epidemiologic research. In ed. Charlottetown, P.E.I., Canada., University of Prince Edward Island. Pp. 865.

Dohoo IR, Martin W, Stryhn H 2009b. Questionnaire Design. In: Dohoo IR, Martin W, Stryhn H ed. Veterinary epidemiologic research. University of Prince Edward Island, Charlottetown, P.E.I., Canada. Pp. 57-72.

Edwards P, Roberts I, Clarke M, DiGuiseppi C, Pratap S, Wentz R, Kwan I 2002. Increasing response rates to postal questionnaires: systematic review. BMJ : British Medical Journal 324: 1183-1183.

Everett KR, Boyd LM, Pak HA, Cutting JGM 2007. Calcium, fungicide sprays and canopy density influence postharvest rots of avocado. Australasian Plant Pathology 36: 22-31.

Everett KR, Taylor RK, Romberg MK, ReesGeorge J, Fullerton RA, Vanneste JL, Manning MA 2011. First report of Pseudomonas syringae pv. actinidiae causing kiwifruit bacterial canker in New Zealand. Australasian Plant Disease Notes 6: 67-71.

Ferrante P, Scortichini M 2009. Identification of Pseudomonas syringae pv. actinidiae as Causal Agent of Bacterial Canker of Yellow Kiwifruit (Actinidia chinensis Planchon) in Central Italy. Journal of Phytopathology 157: 768-770. Ferrante P, Fiorillo E, Marcelletti S, Marocchi F, Mastroleo M, Simeoni S, Scortichini M 2012. The importance of the main colonization and penetration sites of Pseudomonas syringae pv. actinidiae and prevailing weather conditions in the development of epidemics in yellow kiwifruit, recently observed in central Italy. 
Journal of Plant Pathology 94: 455-461.

Froud K, Cogger N 2015. Use of observational study designs and multivariable analysis in plant protection. In: Beresford R, Froud K, Worner SP, Kean J ed. The plant protection data toolbox: On beyond t, F and X Caxton, Christchurch. Pp. 113-120.

Froud K, Cogger N, Beresford R 2014. The relationship between kiwifruit bacterial canker disease (Psa-V (Pseudomonas syringae pv. actinidiae)) and kiwifruit productivity. New Zealand Plant Protection 67: 34-40.

Froud K, Cogger N, Beresford R, Clark G 2015. Orchardist-observed prevalence of symptoms of kiwifruit bacterial canker disease in 'Hayward' kiwifruit blocks in New Zealand. Acta Horticultrae: Proceedings of the 1st International Symposium on Bacterial Canker of Kiwifruit. 1095: 45-48.

Greer G, Teulon D 2003. Farmer survey of yellow dwarf viruses in autumn-sown cereals in Canterbury. New Zealand Plant Protection 56: 257-261.

Groves RM 2006. Nonresponse rates and nonresponse bias in household surveys. Public Opinion Quarterly 70: 646-675.

Groves RM, Peytcheva E 2008. The impact of nonresponse rates on nonresponse bias a meta-analysis. Public Opinion Quarterly 72: 167-189.

Kongsved SM, Basnov M, Holm-Christensen $\mathrm{K}$, Hjollund $\mathrm{NH}$ 2007. Response rate and completeness of questionnaires: A randomized study of Internet versus paperand-pencil versions. Journal of Medical Internet Research 9.

Lonsdale C, Hodge K, Rose EA 2006. Pixels vs. paper: Comparing online and traditional survey methods in sport psychology. Journal of Sport \& Exercise Psychology 28: 100-108.

Mannetje A, Eng A, Douwes J, EllisonLoschmann L, McLean D, Pearce N 2011. Determinants of non-response in an occupational exposure and health survey in New Zealand. Australian and New Zealand Journal of Public Health 35: 256-263.

Neumann EJ, Pearson AB, Sanson RL, Nicoll KJ,
Clement FL 2013. The frequency and distance of movements of pigs and semen between commercial and non-commercial piggeries in New Zealand. New Zealand Veterinary Journal 61: 77-86.

Partin MR, Powell AA, Burgess DJ, Haggstrom DA, Gravely AA, Halek K, Bangerter A, Shaukat A, Nelson DB 2015. Adding Postal Follow-Up to a Web-Based Survey of Primary Care and Gastroenterology Clinic Physician Chiefs Improved Response Rates but not Response Quality or Representativeness. Evaluation \& the Health Professions 38: 382403.

Rolstad S, Adler J, Rydén A 2011. Response Burden and Questionnaire Length: Is Shorter Better? A Review and Meta-analysis. Value in Health 14: 1101-1108.

Rosanowski SM, Cogger N, Rogers XW, Bolwell CF, Benschop J, Stevenson MA 2013. Analysis of horse movements from non-commercial horse properties in New Zealand. New Zealand Veterinary Journal 61: 245-253.

Rothman KJ 2012. Epidemiology: an introduction. Oxford University Press. 267 pp.

Rothman KJ, Greenland S, Lash TL 2008. Modern epidemiology. Lippincott Williams \& Wilkins. 761 pp.

Thebaud G, Sauvion N, Chadoeuf J, Dufils A, Labonne G 2006. Identifying risk factors for European stone fruit yellows from a survey. Phytopathology 96: 890-899.

Van Toor RF, Teulon DAF 2006. Insecticide practice for aphid control in potatoes. New Zealand Plant Protection 59: 235.

Vanneste JL 2012. Pseudomonas syringae pv. actinidiae (Psa): a threat to the New Zealand and global kiwifruit industry. New Zealand Journal of Crop and Horticultural Science 40: 265-267.

Vicent A, Botella-Rocamora P, Lopez-Quilez A, de la Roca E, Bascon J, Garcia-Jimenez J 2012. Relationships between agronomic factors and epidemics of Phytophthora branch canker of citrus in southwestern Spain. European Journal of Plant Pathology 133: 577-584. 